\title{
Creation of Natural Dye Sensitized Solar Cell by Using Nanostructured Titanium Oxide
}

\author{
Lawrence Amadi, Shaichi Sen Jenny, Asif Ahmed, Nikia Brown, Sunil Yadav, Destiny Brown, \\ William Ghann, Alec Gayrama, Mintesinot Jiru, Jamal Uddin* \\ Center for Nanotechnology, Department of Natural Sciences, Coppin State University, USA \\ *Corresponding Author: juddin@coppin.edu
}

Copyright (C) 2015 by authors, all rights reserved. Authors agree that this article remains permanently open access under the terms of the Creative Commons Attribution License 4.0 International License

\begin{abstract}
This research study focused on improving the methodology of producing dye-sensitized solar cells (DSSC) by the process of amalgamation with natural dyes. This research is done with the hope of maximizing cell efficiency and sustainable power production for mass manufacturing processes at the most economical cost. The construction of DSSC is a three-step process comprising: dye extraction, $\mathrm{TiO}_{2}$ paste application, and solar cell structure. These important factors contribute significantly to the efficiency maximization of a dye-sensitized solar cell. This research work conducted specifically explored different ways of improving the current-voltage potential of the solar cells. The solar cell's performance in terms of efficiency and power output (voltage vs. current) was tested under an indoor room light, a halogen lamp and direct sunlight. The experimental results show that the dye extract from Green Cabbage produced the greatest photoelectric conversion efficiency $(\eta)$ of up to $0.1 \%$, an open-circuit voltage $\left(V_{O C}\right)$ of $532 \mathrm{mV}$, and a short-circuit current density (Jsc) of $1.2 \mathrm{~mA} / \mathrm{cm}^{2}$.
\end{abstract}

Keywords: Natural Vegetables Dyes, Titanium-Dioxide $\left(\mathrm{TiO}_{2}\right)$, Fluorine-doped Tin Oxide (FTO), Dye Sensitized Solar Cell (DSSC)

\section{Introduction}

\subsection{Background}

With oil, gasoline, and diesel prices increasing due to the massive dependence on fossil fuels, the world needs an alternative source of energy that is renewable, economical, and environmentally friendly. The focus of this project is to study and discover methods of improving the efficiency of Dye Sensitized Solar Cells using inexpensive natural sensitizers or dyes. Findings from this research could ultimately facilitate the mass production of dye-sensitized solar cells.

Amongst solar photovoltaic, DSSC are an efficient and affordable type of solar cell. The DSSC was first reported in 1972 as a chlorophyll-sensitized zinc oxide ( $\mathrm{ZnO})$ electrode [1]. The function of a DSSC is similar to the role of chlorophyll in plants; it harvests solar light and transfers the energy into an electron capture (in this case $\mathrm{TiO}_{2}$ ) [2]. This discovery led to the realization of the promising potential of DSSC to harness photons for the generation of electric current. In the initial growth of DSSC's, the solar cell's peak efficiency, as reported by Charles Frits, benchmarked at a $1 \%$; as of now, the gold standard vastly improved to a $12 \%$ incident photon current efficiency (IPCE) [3]. New strategies are currently being developed to optimize the performance of DSSC.

\subsection{Science and Function of a Dye-sensitized Solar Cell}

It all starts with the power of the sun. The discovery of the photon by Albert Einstein initiated the process of the fundamentals in regards to photovoltaic cells [5]. The sun and other light sources such as lamps provide tiny packets of energy called photons. Photovoltaic devices, like the solar cell, utilize these photons to produce electricity. Photovoltaic (PV) effect was discovered by Becquerel when he conducted experiments involving illuminated metal electrode in an electrolyte [6]. When the surface of a solar cell is exposed to a light source, the photons strike the surface of the solar cell, causing the electrons on the surface of the solar cell to be excited. These excited electrons undergo other processes to generate electricity. Today, the physics and discipline of the photovoltaic process is fairly well understood. Wafer-based silicon solar cells currently dominate the solar market with efficiencies reaching as high as 20\%. Despite Silicon's lead on the market, DSSC's offer a competitive advantage, in terms of affordability and production.

\subsection{Structure of Dye-sensitized Solar Cell}

A DSSC is generally composed of a photoactive (PV) semiconductor, working electrode of titanium dioxide, and a counter electrode such as Carbon Soot [7]. The dye used in DSSC acts as a photosensitizer allowing solar energy to be converted to electrical energy [8]. The type of dye used in a solar cell is one of the most crucial components influencing solar cell performance as the sensitizer is what determines the photo response of the DSSC [9-10]. The dye is contained in the photo-anodes that are responsible for better absorbance and stronger electron excitation properties, conclusively granting more efficient solar cell [11-17]. 
When incident photons on a DSSC are being absorbed by the photo-anodes, electrons are excited from the ground state to the excited state and subsequently transferred to the conduction band of the $\mathrm{TiO}_{2}$. This process oxidizes the photo-anodes causing the electrons to travel through the electrolyte to the cathode of the cell and returns back to the anode via the circuit. This reoccurring process of moving charges generates electricity.

\subsection{Natural Sensitizers}

Several studies have been reported in the past about the optical properties of dyes such as Anthocyanin and Chlorophyll [18-23]. Anthocyanin's are brightly colored pigments found in plants and may have different colors depending on the $\mathrm{pH}$. Chlorophyll, on the other hand, refers to a group of closely related green pigments found in green colored vegetables and leaves such as Spinach, Green Cabbage, and Lettuce [24-30]. Synthetic chlorophyll and anthocyanin have been developed for the production of solar cells. Synthesis of these dyes could be controlled to obtain concentrated and minute dye particles vital for obtaining higher photoelectric conversion efficiency of solar cells. The cost of production of these dyes is however very high. Therefore someone need to prove and discover a potential natural source of a dye with the best photoelectric conversion efficiency to improve DSSC productivity. Since natural dyes are cheaper to obtain, it would be more economical to mass produce DSSC that could be used in appliances as portable chargers or integrated into building facades [31-33]. The aim of this work was to investigate and determine the most efficient natural dye and to find a consistent and reliable method for producing the cells.

\section{Hypothesis}

\subsection{Application of $\mathrm{TiO}_{2}$ Paste}

A dye-sensitized solar cell consists of two main parts; the Fluorine-doped Tin Oxide (FTO) conductive glass slides (cathode and anode). The anode slide (Fig.1a) contains the $\mathrm{TiO}_{2}$ paste, which absorbs the natural dye and acts as a semi-conductor. The cathode slide (Fig. 1b), however, is covered with carbon soot. The quality of the $\mathrm{TiO}_{2}$ paste and the dexterity to which it is applied on the FTO glass slide contribute significantly to the efficiency of the solar cell. When the two slides are combine together, the $\mathrm{TiO}_{2}$ paste comes in contact with the carbon soot to close the circuit. Therefore to ensure that electron transfer between anode and cathode conductors is optimized, it is essential that the paste is uniformly flattened out on the glass slide to maximize surface area contact.

\subsection{Homogeneity of Liquid Particles}

It is also interesting to know how the homogeneity of natural dye affects the efficiency of a solar cell. Considering the photon and ultraviolet light wave absorption occur in nano-size levels, one can assume the natural dyes used for this research should be homogenous and free from particles for enhancement of complete molecular adsorption to the $\mathrm{TiO}_{2}$ paste. The dyes used in experiment is subjected to rigorous purification processes to investigate the DSSC power output productivity.

\section{Experimental Section}

\subsection{Dye Extraction Process}

The efficiency of a cell depends largely on the homogeneity of the natural dye extract. In order to achieve this desired homogeneity, vegetable samples are extracted through a very rigorous process. First, the samples were washed with pure water, cut into smaller pieces and finely blended. The blended samples were then filtered and the filtrate centrifuged to obtain a homogeneous dye extract.

\subsection{Assembling a Complete Dye-sensitized Solar Cell}

To couple anode and cathode slide two clips on opposite sides are used to hold both slides in position with their sensitive surfaces in contact. Some electrolyte is applied in-between the slides and cables are attached to the anode and cathode terminals of the cell to collect readings.

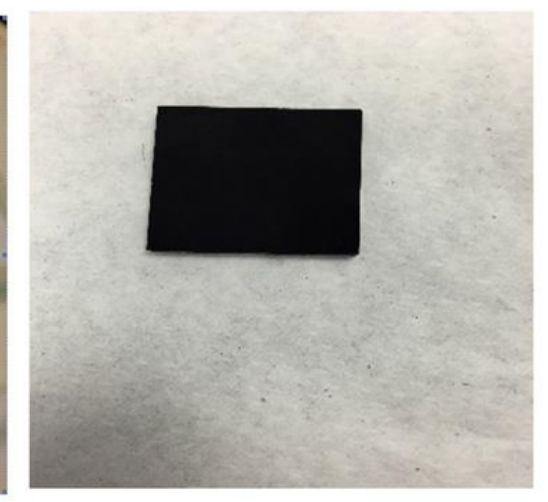

(b)

(a)

Figure 1. (a) $\mathrm{TiO}_{2}$ paste on FTO coated slide; (b) FTO slide with carbon soot 

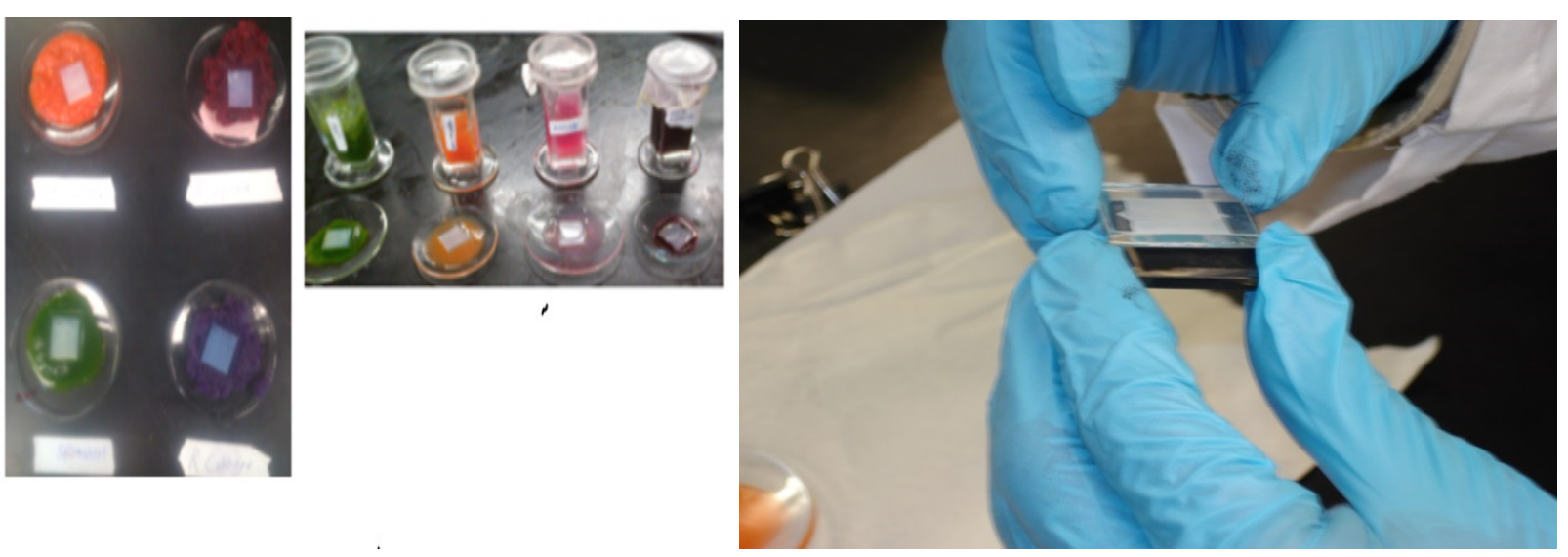

(a)

(b)

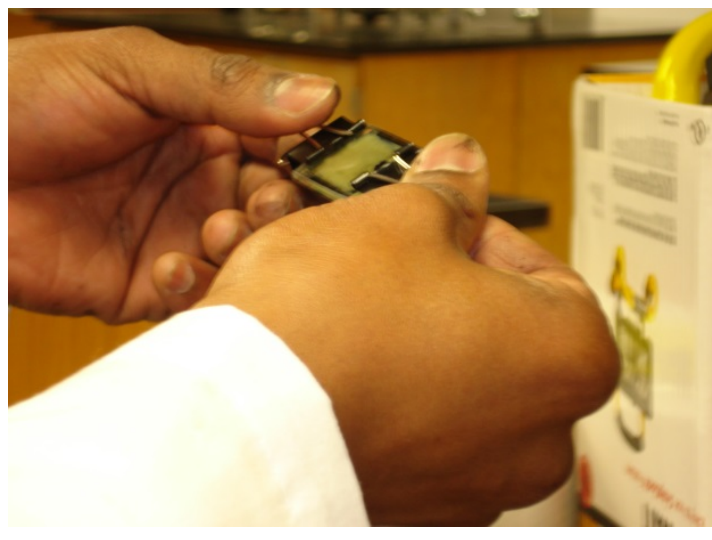

(c)

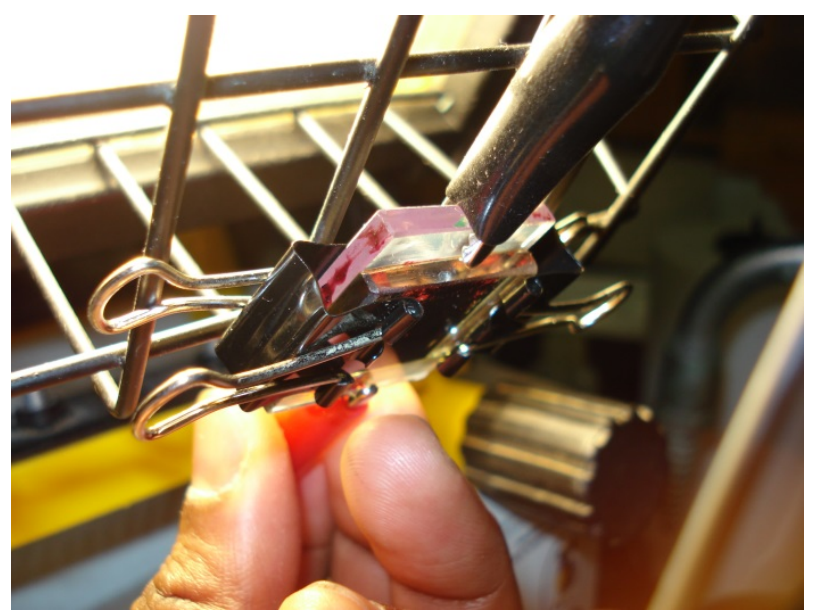

(e)

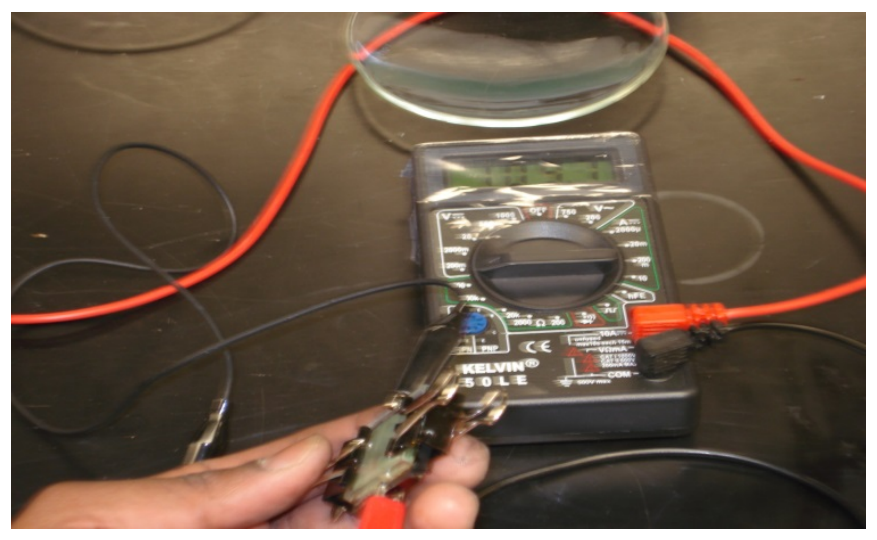

(d)

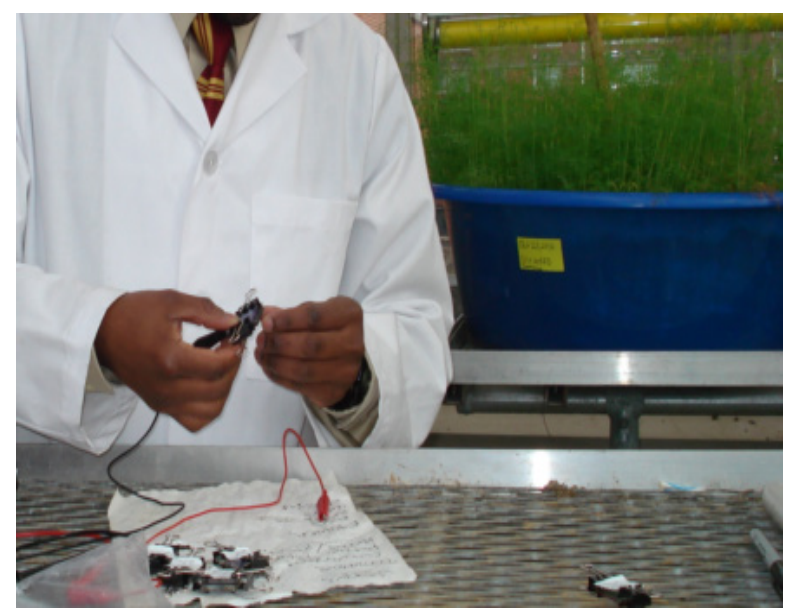

(f)

Figure 2. (a) Natural vegetable dye-sensitizers; (b) $\mathrm{TiO}_{2}$ coated slide (top) placed over carbon coated slide (bottom); (c) Using binder clips to sandwich anode (top) and cathode (bottom) slides; (d) Testing solar cell's voltage using a multi-meter in indoor light; (e) Testing of solar cell under a halogen lamp; (f) Testing solar cell in direct sunlight.

\subsection{Methodology}

To prepare the $\mathrm{TiO}_{2}$ paste, $3.5 \mathrm{ml}$ of concentrated acetic acid is added to $0.8 \mathrm{~g}$ of titanium dioxide powder and the mixture vigorously stirred with a pestle and a mortar until a fine, pasty, white substance is obtained. The conductive face of the FTO glass slide, which should read about $34 \mathrm{ohms}$, is held rigidly face-up on a flat surface using a clear tape. The clear tape is placed in such in a way as to cover a 3-4 $\mathrm{mm}$ area from the edge of the FTO slide on three sides, thereby drawing a border. The tape also ensures that the thickness (about $40-50 \mathrm{~nm}$ ) of the $\mathrm{TiO}_{2}$ paste to be applied remains uniformed across the glass surface. The prepared $\mathrm{TiO}_{2}$ paste is then applied on FTO slide after which a spin coater is used to spread the paste over the glass slide. As shown in Figure 
(1a), it is desirable that a very smooth, equally dispersed $\mathrm{TiO}_{2}$ paste covers the glass slide. The clear tapes are subsequently removed and the glass slides placed on a $120^{\circ} \mathrm{C}$ hot plate for about 60 minutes. The temperature of the hot plate is increased by $10^{\circ} \mathrm{C}$ every 4 minutes. Slide A is then allowed to cool back to room temperature and placed face down in a petri-dish containing the desired vegetable dye extract (Figure.1b, Figure.2a). The glass slide is left sitting in the dye for a minimum of 50 minutes for proper and adequate adsorption of the vegetable dye into the $\mathrm{TiO}_{2}$ paste. After adsorption, the anode slide is rinsed with distilled water and dried with acetone.

To prepare the cathode slide, the sensitive part of the FTO slide with similar resistance as the anode slide is placed over a candle light until it is completely covered with black carbon soot. Next, using a cotton swab about $3 \mathrm{~mm}$ width of soot is removed from three edges of the glass slide creating a border similar to that of the anode slide. The two conductive sides are then coupled together like a sandwich using a pair of binder clips (Figure 2b). Finally, a few drops of iodine electrolyte is added in between the two slides to ensure connectivity (Figure 2c). As shown in Figure 2c, the dye-sensitized solar cell is complete and would immediately be use to put photon incident beam on its surface area.

\section{Results and Discussion}

\subsection{Optical Measurements of Chlorophyll Extract}

The extracted vegetables dyes were characterized using UV-Vis, Fluorescence spectrophotometry and Dynamic light scattering. UV-Vis spectra provided information about the frequencies at which the dyes absorb photons and also quantify the absorbed light. Fluorescence spectra provide insight into emission characteristics of the dyes whereas dynamic light scattering give particle size analysis of the dyes

\section{Absorbance Spectrum of Chlorophyll Extracted from Green Cabbage}

UV-Vis spectra of dye extract from green cabbage (Figure 3) shows a strong absorbance in the blue region $(436 \mathrm{~nm})$ and another intense absorption band in the red region $(670 \mathrm{~nm})$. The extract from green cabbage mainly contains chlorophyll and two intense absorption bands in the visible region are indicate the presence of this pigment. Two absorption peaks represent the pigment of chlorophyll a and chlorophyll $\mathbf{b}$. Thus chlorophyll absorbs visible light which is used in the production of carbohydrate.

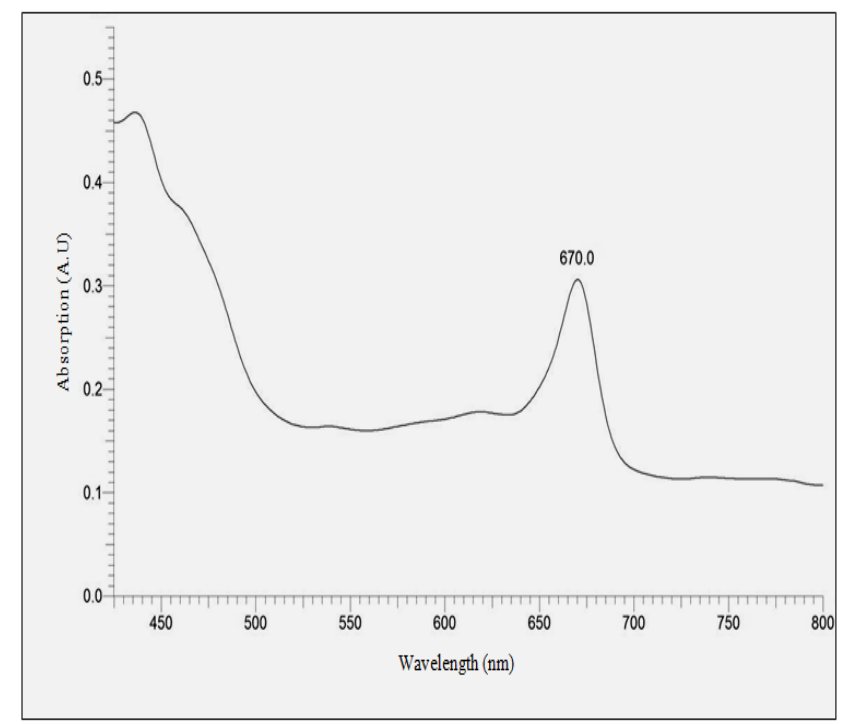

Figure 3. Absorption spectrum of dye extract from Green Cabbage

\section{Fluorescence Spectrum of Chlorophyll Extracted from Green Cabbage}

The Fluorescence spectrum was recorded from a wavelength of $350 \mathrm{~nm}$ to $800 \mathrm{~nm}$ (Figure 4). The understanding of the performance of a chlorophyll based DSSC could be obtained by examining the emission of the dye and determining the energy level distribution. The peak maxima were observed at $507 \mathrm{~nm}$ and $684 \mathrm{~nm}$. The Emission is stimulated at various energized wavelengths and the intensity of the discharged fluorescence is measured as a function of wavelength. The amplitude of the peaks seen in the emission spectrum is directly proportional to the number of photons that are emitted.

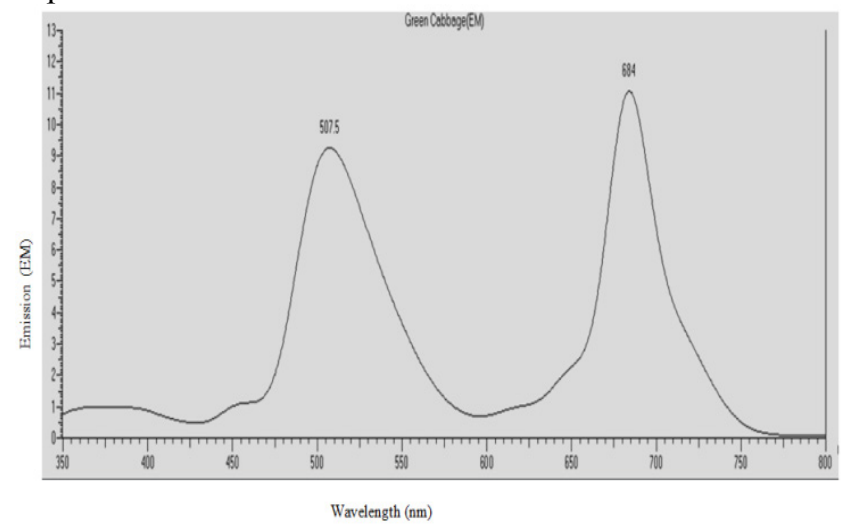

Figure 4. Fluorescence spectrum of dye extract from Green Cabbage

\section{Particle Size Analysis of Chlorophyll Extract from Green Cabbage}

Using dynamic light scattering, the sizes of the dye particles were analyzed as displayed in Figure 5. The particles sizes of the chlorophyll form the green cabbage pigment was found to 3-4 microns in diameter at a frequency 
of a little more than $13 \%$. The frequency gives information about how far apart the particles are and how much of light bounces off the particles in the suspension. According to this data as shown in Figure (5), the dye will be well adsorbed unto the titanium dioxide and still be able to absorb a high amount of sunlight.

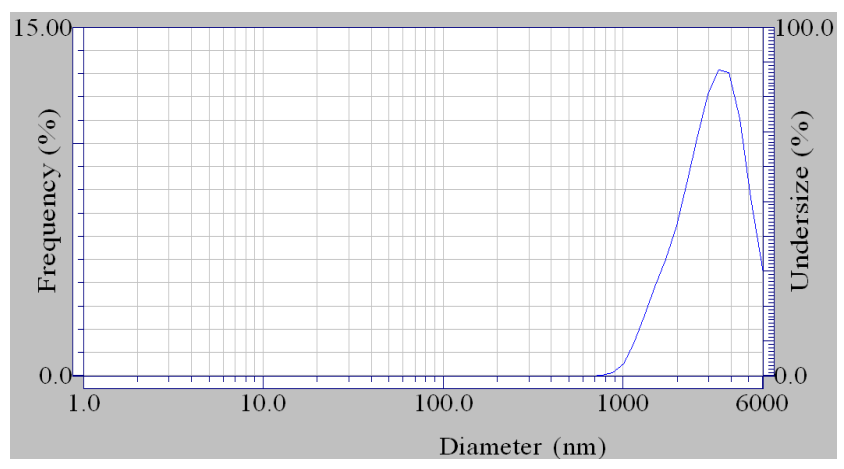

Figure 5. Particle size analysis of dye extract from Green Cabbage

When the sizes of the particles in the dye are known, an understanding of how intensely the light will be absorbed and reflected by the particles in the dye could be attained. The size of the particles act as crucial role to increase the efficiency of the cell and must measure for optimum output.

\subsection{Voltage \& Current Data for all Natural Dyes}

The measurement of the power (voltage and current) generated by the dye-sensitized solar cells were carried out under three different conditions: Indoor light (Figure 2d), halogen lamp (Figure 2e), and direct sunlight (Figure 2f). The goal was to investigate the highest combination of voltage and current produced by the solar cells. These solar cells were made with dye extract from 16 different vegetable samples. Each sample's voltage and current were averaged when tested under each light source for 3 minutes.

The current and voltage data of the various 16 vegetable samples are displayed in Figures 6 and 7. The data records the voltage and current attained by the dye-sensitized solar cell. Each solar cell was tested 5 times and the average voltage and current of the solar cells are shown in Figures 8 and 9 .

Multiple trial readings were taken for each of the 16 samples and measurements were carried out under indoor light, halogen lamp and direct sun light. The data recorded under direct sunlight was more consistent than the indoor and halogen light source data. The readings from each dye sample generated sets of numbers that varied significantly. After calculating the statistical deviation on the sets of numbers, it was found that the distribution of the indoor and halogen light readings was random. Direct sunlight clearly produce more photons than indoor and halogen lamp light source. The measurements performed in an indoor and halogen lamp light source generated low photo conversion efficiency. Upon confirming that sunlight was the best light source, the top performing six vegetable samples were selected for further measurement under direct sunlight.

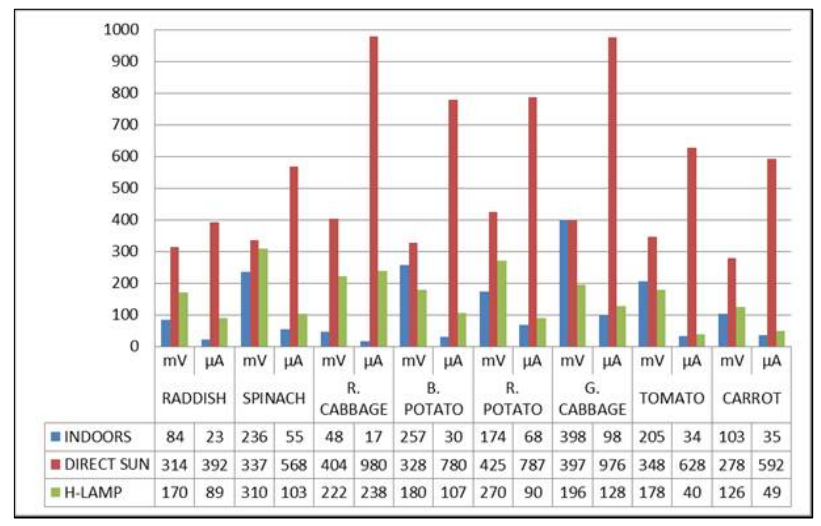

Figure 6. Voltage and current data for anthocyanin/chlorophyll dye

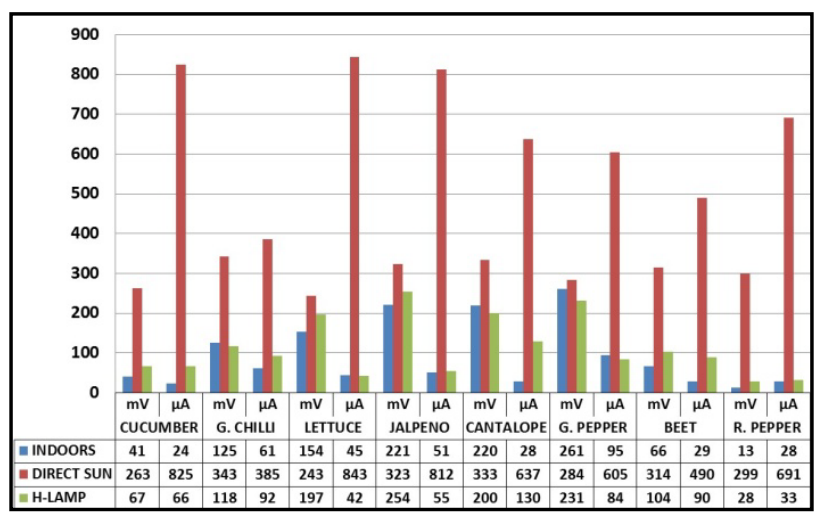

Figure 7. Voltage and current data for anthocyanin/chlorophyll dye continued

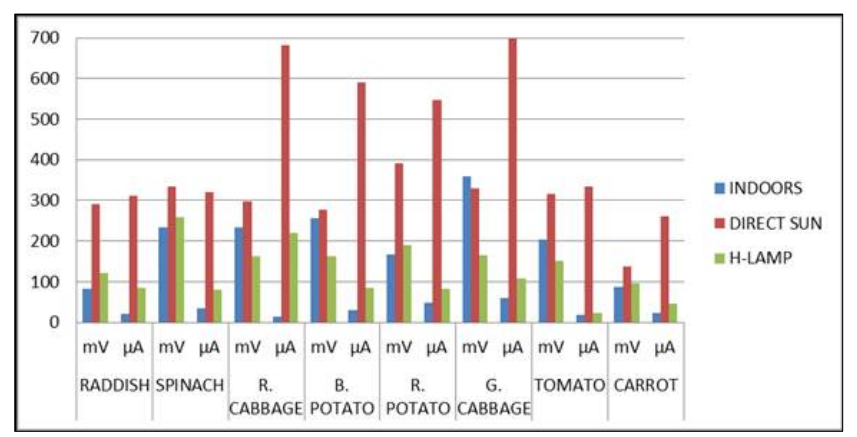

Figure 8. Average voltage and current data or anthocyanin/chlorophyll dye

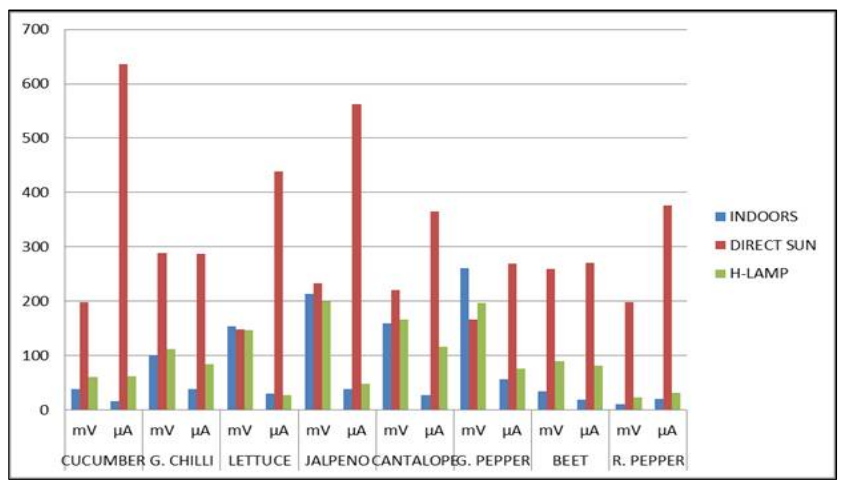

Figure 9. Average voltage and current data continued 


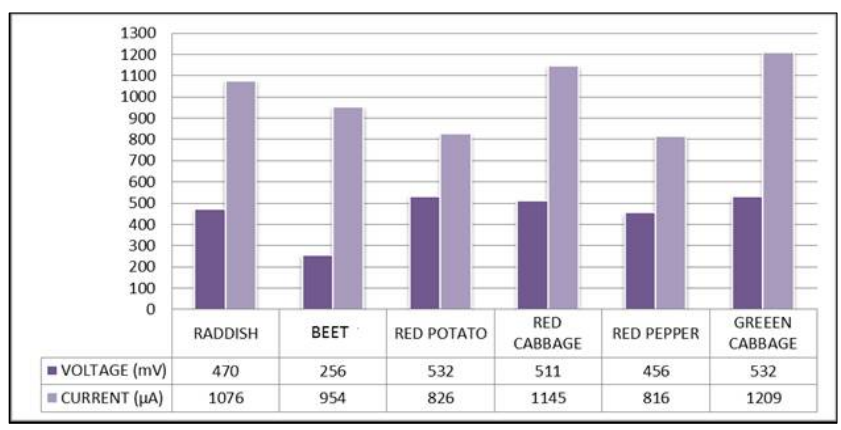

Figure 10. Direct sunlight data for anthocyanin and chlorophyll dye (centrifuge)

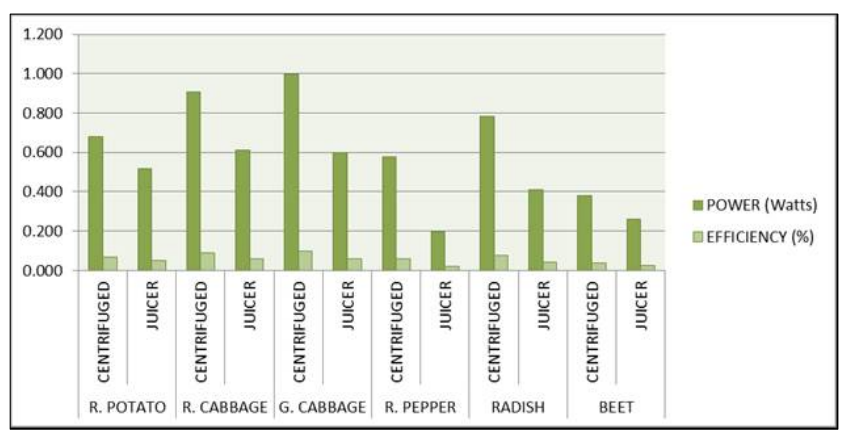

Figure 11. Comparison of centrifuge and juice dye (power and efficiency performance)

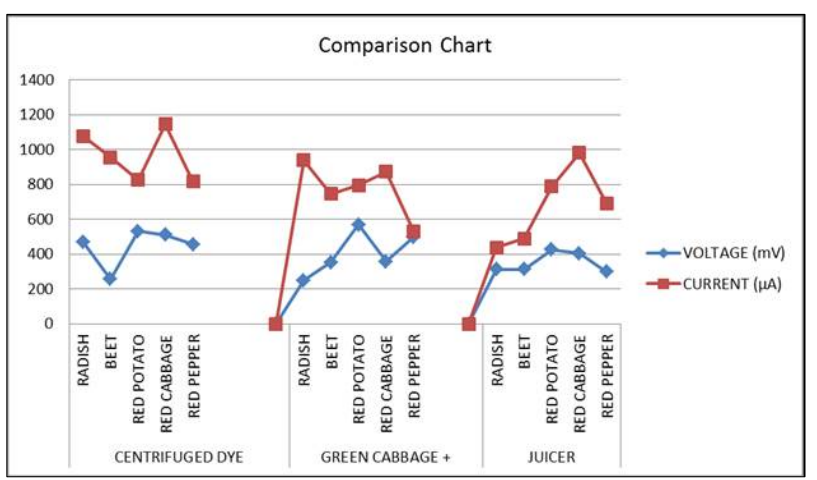

Figure 12. Comparing of anthocyanin \& chlorophyll mixed dye (voltage and current performance)

The vegetable dye sensitizer were centrifuged to remove all kinds of fibers or impurities. Solar cell slides are placed on a white surface (a white A4 paper) while measuring the current and voltage output. White background surface have been observed to significantly improve the efficiency of the dye-sensitized solar cell. Figure (10) exhibits the consistent and high productivity of the red and green cabbage samples. In relation to this data, red cabbage's voltage advanced from $404 \mathrm{mV}$ to $511 \mathrm{mV}$, and its current followed an increase in current of $980 \mu \mathrm{A}$ to $1145 \mu \mathrm{A}$. In comparison, green cabbage rose to a voltage of $397 \mathrm{mV} 532 \mathrm{mV}$, and similarly increased in current from $976 \mu \mathrm{A}$ to a more prominent $1209 \mu \mathrm{A}$. All of the six samples demonstrated growth in power production and efficiency after the purification process by using a juicer and high vacuum centrifuge [Fig11].

\subsection{DSSC Power and Efficiency Formula and Calculations}

\author{
Power $(\mathrm{P})=$ Current $\times$ Voltage \\ Surface Area of ITO (S.A) $=(1 \text { inch })^{2}=0.000645 \mathrm{~m}^{2}$ \\ Power Output $\left(\mathrm{P}_{\text {cell }}\right)=$ Power $/$ Surface Area \\ Solar Power Constant $\left(\mathrm{P}_{\text {AM 1.5 }}\right)=1000 \mathrm{~W} / \mathrm{m}^{2}$ \\ Efficiency $(\eta)=P_{\text {cell }} / P_{\text {AM } 1.5} \times 100$ \\ For Green Cabbage: \\ $\mathrm{P}=\mathrm{I} \times \mathrm{V}=\left(1.21 \times 10^{-3}\right) \mathrm{A} \times\left(532 \times 10^{-3}\right) \mathrm{V}=644 \times 10^{-6} \mathrm{~W}$ \\ $\mathrm{P} / \mathrm{S} . \mathrm{A}=644 \times(10)^{-6} \mathrm{~W} / 0.000645 \mathrm{~m}^{2}=0.99 \mathrm{~W} / \mathrm{m}^{2}$ \\ $\eta=\mathrm{P}_{\text {cell }} / \mathrm{P}_{\mathrm{AM} 1.5} \times 100=\left(0.99 \mathrm{~W} / \mathrm{m}^{2}\right) /\left(1000 \mathrm{~W} / \mathrm{m}^{2}\right) \times 100$ \\ $=.099 \approx .1 \%$ efficiency
}

The highest power per surface area produced by the vegetable dye-sensitized solar cell so was approximately 1 Watts (Fig 11). Chlorophyll from Green Cabbage generated this power output, giving the cell an efficiency of $0.1 \%$. Dye extract from Red Cabbage produced power output of 0.9 Watts and a cell efficiency of $0.091 \%$. Radish and Red Potato dye extracts had power output of 0.6 Watts and a cell efficiency of $0.06 \%$. The vegetable dyes extract used in this study are known to contain either chlorophyll/ anthocyanin pigments which are responsible for transforming photons to electric charges. The green colored vegetable samples like Spinach, Jalapeno, Green Cabbage and Lettuce contains chlorophyll, while the brightly colored samples such as Red Cabbage, Red Potato, Beet and Radish contain a high concentration of the anthocyanin pigment.

To improve the efficiency of the vegetable dye-sensitized solar cell, the role of chlorophyll or anthocyanin plays in power production which was investigated. The experiment was conducted with a mixture of two dye extracts or one containing chlorophyll and the other anthocyanin. Previous studies indicate that the chlorophyll-based dyes generate more voltage than anthocyanin-based dyes whereas anthocyanin-based dyes create more current. The initial hypothesis was: using a hybrid dye engineered by mixing two vegetable dyes containing anthocyanin and chlorophyll molecules will improve the cell's power output produced based on the dyes' viability. We estimated that exploiting the voltage producing power of chlorophyll based dyes and the current producing power of anthocyanin-based dyes would significantly improve the cells efficiency. Since Green Cabbage contains the most efficient chlorophyll based dye, it was mixed with the other five anthocyanin-based dyes. Figure (12) displays the current and voltage production from the mixed vegetable dye extracts, the centrifuged dyes, and vegetables dye extract from the juicer. Contrary to the initial prediction, mixing chlorophyll and anthocyanin based dyes in their natural state did not improve power production. The dye-sensitized solar cell slides were less efficient. Voltage and current production reduced significantly with the exception of Red Potato whose voltage was increased from $532 \mathrm{mV}$ to $569 \mathrm{mV}$, but the current dropped from $826 \mu \mathrm{A}$ to $794 \mu \mathrm{A}$. 
This reduction in efficiency might be because the expected fusion of the two different dyes did not occur after simply shaking the mixture vigorously in a test tube. More studies will be carried out to investigate the best method by which the anthocyanin and chlorophyll based dyes could be mixed to improve the cell efficiency and performance.

\section{Conclusion}

The work conducted during this research aimed at optimizing the DSSC using three strategies: the use of vegetable organic sensitizers to make stable and efficient DSSCs, the role of anthocyanin and chlorophyll dyes, and the amalgamation of these dyes to harvest a larger fraction of the solar spectrum. As discussed in the respective data, a few contributions have been made:

1. Natural Sensitizers: Of the tested natural sensitizers, low photo conversion efficiency of $0.1 \%$ was calculated dye extract from green cabbage. Multiple organic sensitizers have been tested and observed chlorophyll dye has stronger voltage production and anthocyanin dye has stronger current output.

2. Testing Environment: The measurements were conducted indoor light, under a halogen lamp and direct sunlight provided consistent data in terms of efficiency, power, voltage, and current.

3. Purification Process: Having rigorous purification process, the macro dye particles were centrifuged and filtered to ensure homogenous and small nano-sized particles are well absorbed into the $\mathrm{TiO}_{2}$ paste. This improves the photon to energy conversion efficiency of the cell, leading to an even higher max-power output.

4. Mechanism of Electrolyte: As of now, the method used in the application of the electrolyte is mediocre. The liquid electrolyte evaporates from the unsealed solar cell after a few minutes causing a drop in power output. If this problem is addressed it will sustain a steady power output.

\section{Acknowledgements}

We are thankful to Constellation, an Exelon Company ( $E^{2}$ Energy to Educate grant program) for financial support. In addition, we would like to acknowledge Institution of Advancement, Coppin State University, for administrative help.

\section{REFERENCES}

[1] Fritz, Charles Edward. Disaster. Institute for Defense Analyses, Weapons Systems Evaluation Division, 1961

[2] McKinney, Gr. "Absorption of light by chlorophyll solutions." Journal of Biological Chemistry 140.2 (1941): 315-322.

[3] Fritz, Charles E, and John H Mathewson. Convergence behavior in disasters: A problem in social control: A special report prepared for the Committee on Disaster Studies. National Academy of Sciences National Research Council, 1957.

[4] Fritz, Charles E, and Eli S Marks. "The NORC studies of human behavior in disaster." Journal of Social Issues 10.3 (1954): 26-41.

[5] Einstein, Albert. "The photoelectric effect." Ann. Phys 17 (1905): 132.

[6] Becquerel, Alexandre-Edmond. "Mémoire sur les effets électriques produits sous l'influence des rayons solaires." Comptes Rendus 9.567 (1839): 1839.

[7] Pradhan, Basudev, Sudip K Batabyal, and Amlan J Pal. "Vertically aligned $\mathrm{ZnO}$ nanowire arrays in Rose Bengal-based dye-sensitized solar cells." Solar Energy Materials and Solar Cells 91.9 (2007): 769773.

[8] Grätzel, Michael. "Dye-sensitized solar cells." Journal of Photochemistry and Photobiology C: Photochemistry Reviews 4.2 (2003): 145-153.

[9] Hara, Kohjiro, and Hironori Arakawa. "Dye-sensitized solar cells." Handbook of photovoltaic science and engineering 6634696 (2003).

[10] "How do Photovoltaics Work? - NASA Science." November 2014

[11] Kalyanasundaram, Kuppuswamy. Dye-sensitized solar cells. Kuppuswamy Kalyanasundaram. EPFL press, 2010.

[12] Hara, Kohjiro, and Hironori Arakawa. "Dye-sensitized solar cells." Handbook of photovoltaic science and engineering $6634696(2003)$

[13] Zaban, Arie, Miri Greenshtein, and Juan Bisquert. "Determination of the Electron Lifetime in Nanocrystalline Dye Solar Cells by Open-Circuit Voltage Decay Measurements." ChemPhysChem 4.8 (2003): 859-864.

[14] Fabregat-Santiago, Francisco et al. "Electron transport and recombination in solid-state dye solar cell with spiro-OMeTAD as hole conductor." Journal of the American Chemical Society 131.2 (2008): 558-562.

[15] Cesar, Ilkay et al. "Translucent thin film $\mathrm{Fe}_{2} \mathrm{O}_{3}$ photoanodes for efficient water splitting by sunlight: nanostructure-directing effect of Si-doping." Journal of the American Chemical Society 128.14 (2006): 4582-4583.

[16] Hinsch, Andreas. "Dye solar cells." Anwendungen der Nanotechnologie in Architektur und Bauwesen.. Future Technologies (2006): 167e76.

[17] Bahadur, Karki Indra et al. "Dye-Sensitized Solar cell using extract of Punica Granatum L. Pomegranate (Bedana) as a Natural Sensitizer." Research Journal of Chemical Sciences ISSN 2231 (2012): 606X

[18] Hodges, D Mark et al. "Improving the thiobarbituric acid-reactive-substances assay for estimating lipid peroxidation in plant tissues containing anthocyanin and other interfering compounds." Planta 207.4 (1999): 604-611.

[19] Holton, Timothy A, and Edwina C Cornish. "Genetics and biochemistry of anthocyanin biosynthesis." The Plant Cell 7.7 (1995): 1071. 
[20] Prior, Ronald L et al. "Antioxidant capacity as influenced by total phenolic and anthocyanin content, maturity, and variety of Vaccinium species." Journal of Agricultural and Food Chemistry 46.7 (1998): 2686-2693.

[21] Mackinney, Gr. "Absorption of light by chlorophyll solutions." Journal of Biological Chemistry 140.2 (1941): 315-322.

[22] Porra, RJ, WA Thompson, and PE Kriedemann. "Determination of accurate extinction coefficients and simultaneous equations for assaying chlorophylls, extracted with four different solvents: verification of the concentration of chlorophyll standards by atomic absorption spectroscopy." Biochimica et Biophysica Acta (BBA)-Bioenergetics 975.3 (1989): 384-394.

[23] O'regan, Brian, and M Grätzel. "A low-cost, high-efficiency solar cell based on dye-sensitized." nature 353 (1991): 737-740.

[24] Green, Martin A et al. "Solar cell efficiency tables (version 39)." Progress in photovoltaics: research and applications 20.1 (2012): 12-20.

[25] Repins, Ingrid et al. "19. 9\%-efficient $\mathrm{ZnO} / \mathrm{CdS} / \mathrm{CuInGaSe}$ solar cell with $81 \cdot 2 \%$ fill factor." Progress in Photovoltaics. Research and applications 16.3 (2008): 235-239.

[26] Smith, Joseph Mauk. "Introduction to chemical engineering thermodynamics." Jan. 1975.

[27] Cengel, Yunus A, Michael A Boles, and Mehmet Kanoğlu. Thermodynamics: an engineering approach. New York: McGraw-Hill, 2011.

[28] Cox, JD, Donald D Wagman, and Vadim Andreevich Medvedev. CODATA key values for thermodynamics. Chem/Mats-Sci/E, 1989.

[29] De Groot, Sybren Ruurds, and Peter Mazur. Non-equilibrium thermodynamics. Courier Dover Publications, 2013.

[30] Truesdell, Clifford, and Ralph Baierlein. "Rational thermodynamics." American Journal of Physics 53.10 (1985): $1020-1021$

[31] Mackinney, Gr. "Absorption of light by chlorophyll solutions." Journal of Biological Chemistry 140.2 (1941): 315-322.

[32] Genty, Bernard, Jean-Marie Briantais, and Neil R Baker. "The relationship between the quantum yield of photosynthetic electron transport and quenching of chlorophyll fluorescence." Biochimica et Biophysica Acta (BBA)-General Subjects 990.1 (1989): 87-92.

[33] Yentsch, Charles S, and David W Menzel. "A method for the determination of phytoplankton chlorophyll and phaeophytin by fluorescence." Deep Sea Research and Oceanographic Abstracts 31 Jul. 1963: 221-231.

[34] Kooten, Olaf, and Jan FH Snel. "The use of chlorophyll fluorescence nomenclature in plant stress physiology." Photosynthesis Research 25.3 (1990): 147-150.

[35] Cheng, Yen-Ju, Sheng-Hsiung Yang, and Chain-Shu Hsu. "Synthesis of conjugated polymers for organic solar cell applications." Chemical Reviews 109.11 (2009): 5868-5923.

[36] Papageorgiou, $\mathrm{N}$ et al. "The performance and stability of ambient temperature molten salts for solar cell applications." Journal of the Electrochemical Society 143.10 (1996): 3099-3108.

[37] Green, Martin A. "Solar cells: operating principles, technology, and system applications." Englewood Cliffs, $N J$, Prentice-Hall, Inc., 1982. 288 p. 1 (1982).

[38] Beaujuge, Pierre M, and Jean MJ Fréchet. "Molecular design and ordering effects in $\pi$-functional materials for transistor and solar cell applications." Journal of the American Chemical Society 133.50 (2011): 20009-20029. 